\title{
Effects of COVID-19 on the Musculoskeletal System: Clinician's Guide
}

\section{Laith $\mathrm{K}$ Hasan \\ Brittney Deadwiler \\ Aryan Haratian \\ loanna K Bolia (D) \\ Alexander E Weber \\ Frank A Petrigliano}

USC Epstein Family Center for Sports Medicine at Keck Medicine of USC, Los Angeles, CA, USA
Correspondence: Frank A Petrigliano USC Epstein Family Center for Sports Medicine at Keck Medicine of USC, 1520 San Pablo st\#2000, Los Angeles, CA, 90033, USA

Tel + I 310 403-044I

Email fpetrigliano@gmail.com

\begin{abstract}
The global pandemic caused by SARS-CoV-2, or COVID-19, continues to impact all facets of daily life. Clinical manifestations of COVID-19 commonly include musculoskeletal symptoms such as myalgias, arthralgias, and neuropathies/myopathies. The inflammatory response and its impact on the respiratory system have been the focus of most studies. However, the literature is more limited regarding the inflammatory response and its implications for other organ systems, specifically the musculoskeletal system. Previous studies have described how systemic inflammation may play a role in bone and joint pathology. Furthermore, it is important to understand the effects current therapeutics used in the treatment of COVID-19 may have on the musculoskeletal system. In this study, we will review the current understanding of the effect COVID-19 has on the musculoskeletal system, provide an overview of musculoskeletal symptoms of patients infected with the virus, and address key issues for clinicians to address during the care of COVID-19 patients. Keywords: COVID-19, musculoskeletal system, SARS-CoV-2
\end{abstract}

\section{Introduction}

The global pandemic caused by SARS-CoV-2, or COVID-19, continues to impact all facets of daily life. Those infected with COVID-19 can vary widely in presentation, ranging from asymptomatic to severely ill and in critical condition. While COVID-19 is primarily a respiratory disease, numerous studies have documented and reported the various extra-pulmonary manifestations and symptoms. Clinical manifestations of COVID-19 commonly include musculoskeletal (MSK) symptoms such as myalgias, arthralgias, and neuropathies/myopathies. One study observed that of 12,046 patients, myalgia and/or arthralgia were present in $15.5 \%$ of patients. Consequently, it is crucial for clinicians to understand further and investigate the musculoskeletal symptoms and presentation of those infected with COVID-19.

Additionally, it is imperative to investigate the pathology, and potential mechanisms of the impact COVID-19 has on the musculoskeletal system. Previous studies have demonstrated that infection with the virus induces a proinflammatory state in patients with systemic effects as a result. The inflammatory response and its impact on the respiratory system have been the focus of most studies. However, the literature is more limited regarding the inflammatory response and its implications for other organ systems, specifically the musculoskeletal system. Previous studies have described how systemic inflammation may play a role in bone and joint pathology. Inflammation has also been linked to damage and disease of skeletal muscle. Therefore, investigating the potential impact COVID-19 induced 
inflammation has on musculoskeletal health is essential to adequately understand and treat these symptoms.

Furthermore, it is important to understand the effects current therapeutics used in the treatment of COVID-19 may have on the musculoskeletal system. Current therapy for COVID-19 includes medications such as chloroquine, hydroxychloroquine, colchicine, specific antivirals, and corticosteroids. Many of these medications are associated with toxic myopathies, arthralgias, and other various side effects. Given that the side effect profile of many of these medications overlaps and can potentially mask symptoms that can present with COVID-19, it is important to keep these drug interactions in mind.

In this study, we will review the current understanding of the effect COVID-19 has on the musculoskeletal system, provide an overview of musculoskeletal symptoms of patients infected with the virus, and address key issues for clinicians to address during the care of COVID-19 patients.

\section{Clinical Effects of COVID-I 9 Infection on Musculoskeletal System} Neuromuscular Involvement: Neuropathies \& Myopathies

Reports in the literature have described cases of COVID19 causing neuromuscular damage and symptoms in patients, especially those that are critically ill or of older age with reports of myopathy, polyneuropathy, and Guillain-Barre syndrome. Notably, in a systematic review and meta-analysis of 11,069 patients infected with COVID-19, Abdullahi et al found that there are more neurologic symptoms than musculoskeletal symptoms in COVID-19 patients. Intensive care unit (ICU)-acquired weakness (ICUAW) is an umbrella term used to describe common neuromuscular symptoms in critically ill ICU patients, encompassing critical illness polyneuropathy (CIP), critical illness myopathy (CIM), and the combination of both, critical illness polyneuromyopathy (CIPM). This is especially relevant for COVID-19 patients admitted to the ICU that have undergone invasive ventilation and pronation cycles for respiratory distress, with reports describing cases of patients experiencing critical illness myopathy (CIM) and critical illness polyneuropathy (CIP) as a result. One case series reported that of 225 COVID-19 patients in the ICU in Spain, 12 patients were referred to the neurophysiology department for suspicion of ICUAW, and 11 cases of CIM and CIP were confirmed.
This reported rate of ICUAW in ICU patients with COVID-19 is thought to be underestimated due to patient death prior to diagnosis, the delay and cancellation of nonessential studies due to the infectious nature of the disease, and limited availability of neurophysiology staff and resources. It is essential that clinicians can identify and properly diagnose COVID-19 patients with ICUAW so that these patients may receive early rehabilitation and treatment to improve functional outcomes after recovery. Additionally, it is important to recognize that CIM has a better prognosis than CIP according to published studies and younger patients with CIM are found to have more positive outcomes and recovery of motor skills.

The exact pathophysiology of CIP and CIM is not well understood, especially as it pertains to COVID-19. Risk factors for ICUAW of general causes include multiple organ failure, sepsis, hyperglycemia, mechanical ventilation, and parenteral nutrition. These risk factors are highly prevalent in COVID-19 patients in the ICU. It has also been described how COVID-19-induced inflammation may result in a cytokine storm. CIM is thought to be caused by serious injury to the body with sequential overproduction of cytokines causing microvascular derangement, and metabolic and electrical (channel) alterations. It has been proposed that CIP may be caused by either a storm of systemic inflammation factors (cytokines, nitric oxide and oxygen radicals), creating hypoxic conditions that decreased circulation of local axonal survival factors or by increased vascular permeability from chronic inflammation causing vasogenic edema.

In COVID-19 patients, ICUAW can be diagnosed by assessing peripheral and/or respiratory muscles. The challenge in diagnosing infected patients is that the patients must be awake and cooperative. However, many COVID19 patients are uncooperative due to sedation-induced delirium. In these cases, electromyography and single nerve conduction studies can be used for differential diagnosis. Cabanes et al reported on 12 COVID-19 patients in the ICU that presented with weakness in their upper and lower extremities, accompanied with elevated creatine kinase (CK) levels, elevated D-dimer and lymphopenia. The authors did not find any difference in the presentation of COVID-19-related CIM/CIP from other causes. However, they observed a noticeable degree of spontaneous muscle activity in patients COVID-19 patients with CIM.

In a single-center study looking into differences in outcomes for COVID-19 patients with ICUAW patients, 
Van Aerde et al found that patients with ICUAW spent more days on ventilation $(\mathrm{p}<0.001)$ and had longer stays in the ICU $(p=0.008)$, had higher average glycemia in the morning $(p=0.041)$, lower mobility scores at ICU discharge $(\mathrm{p}<0.001)$, and more treatment with corticosteroids, sedatives and analgesics compared to patients without weakness. COVID-19 patients with CIM and CIP also tend to have difficulty weaning from a ventilator due to respiratory muscle weakness. COVID19-related CIM studies have also highlighted symptoms of severe hypotrophy of the shoulder girdle and/or peroneal district. Studies have found that ICUAW of various etiologies is associated with lower physical functioning at 6 months after discharge from the ICU and higher rates of mortality after discharge from the hospital at 6-months and 1 -year post-ICU. The likelihood of post-ICU mortality is even more striking with more severe weakness (MRC sum score $<36$ ) or weakness that continues until the time of discharge. COVID-19 studies of ICUAW, however, have not found any difference in ICU readmission or ICUrelated mortality rates between ICUAW patients and patients without weakness $(p=0.225,0.491)$. More studies are needed to determine the long-term functional outcomes of COVID-19 patients with ICUAW.

Therapeutic intervention of COVID-19-associated CIM and CIP focus on both prevention and treatment with the goal of increasing patients' chances of returning to their baseline, pre-infection state of function. The prevention aspect of intervention focuses on reducing the time a patient spends in an immobilized state. The treatment aspect focuses on pulmonary rehabilitation and early mobilization. Interventions for pulmonary prevention include incentive spirometry and patient positioning to increase ventilation. Early mobilization of conscious patients and passive mechanical loading for unconscious or sedated patients have been found to increase postdischarge function. One meta-analysis showed that early rehabilitation with mobilization to reduce time spent immobile and/or neuromuscular electrical stimulation to lessen muscle atrophy was associated with a decreased likelihood of developing ICUAW. The authors also found that early rehabilitation had a better effect in studies with patients that spent more time in the ICU. They also found that length of stay in the ICU was numerically shortened in patients with early rehabilitation. Additionally, early rehabilitation in the ICU reduced the odds of developing ICUAW in $37 \%$ of patients that were screened and $29 \%$ in randomized populations. Caution should be taken for patients suffering from sedation-induced delirium, as this can interfere with the ability to complete pulmonary and mobilization intervention due to decreased patient ability, motivation, and cooperation.

There have also been several documented cases of Guillain Barre Syndrome (GBS) arising in hospitalized COVID-19 patients Studies have described how similar to typical GBS, COVID-19-related GBS affects a broad age range but has a higher reported incidence and less favorable outcomes in older patients. Patients with COVID-19-related GBS also tended to have accompanying pneumonia, acute respiratory distress syndrome, and more extensive demyelinating neuropathy.

\section{Inflammation Impact on MSK}

COVID-19-induced inflammation has been found to negatively affect the musculoskeletal system through numerous proposed mechanisms. SARS-CoV-2 utilizes ACE2, a receptor present on many tissue types including smooth muscle, synovial tissue, and cartilage, to enter cells and undergo viral replication. ACE2 has many functions including anti-inflammatory properties and restriction of bone resorption. Tao et al proposed that when SARS-CoV -2 uses the ACE2 receptor to enter cells and blocks receptor function leading to decreased bone mass and joint inflammation. Apoptosis of virally infected cells can lead to more local inflammation. Especially important for COVID-19 patients being treated with a ventilator, long times spent on a ventilator can cause proinflammatory signals that can lead to muscle and bone fragility measured by decreased bone mineral density. Furthermore, COVID19 induces hypoxia which can cause the overproduction of inflammatory cytokines such as receptor activator of nuclear factor-B ligand (RANKL), vascular endothelial growth factor (VEGF), and macrophage colony stimulating factor (M-CSF). Studies have described how these hypoxia-induced molecules may activate osteoclasts and block osteogenesis of osteoblasts, which can lead to increased bone resorption and restricted bone formation.

The inflammatory response to SARS-CoV-2 in the respiratory tract may lead to systemic inflammation that impacts many organ systems including the musculoskeletal system. Studies have described how SARS-CoV-2 infection induces systemic elevations of cytokines and signaling molecules such as CKCL19, IFN- $\gamma$, IL-1 $\beta$, IL6 , IL-8, IL-17 and TNF- $\alpha$. These inflammatory molecules have numerous potential mechanisms by which they may cause musculoskeletal symptoms. IFN- $\gamma$, IL- $1 \beta$, IL-6, IL- 
17 and TNF- $\alpha$ are known to directly impact skeletal muscle by inducing fiber proteolysis and decreasing protein synthesis. IL- $1 \beta$ and IL- 6 may cause fibrosis by inducing increased muscle fibroblast activity. IL- $1 \beta$ and TNF- $\alpha$ have been described to inhibit the differentiation and proliferation of satellite cells, the progenitor cells involved in muscle fiber growth. CXCL10, IL-17 and TNF- $\alpha$ induce osteoclastogenesis and inhibit osteoblast proliferation and differentiation causing increased bone fragility. IL-1 $\beta$, IL6 , and TNF- $\alpha$ induce chondrolysis leading to arthalgia and/ or the progression of osteoarthritis. IL-1 $\beta$, IL-17 and TNF$\alpha$ may contribute to tendinopathy by impairing the biological activity of tenocytes. Therefore, these inflammatory molecules may be involved in the decreased muscle strength and endurance and increased bone fragility associated with COVID-19 infection.

COVID-19 may also be a cause of inflammatory reactive arthritis, which presents similarly to rheumatoid arthritis. One case report described 5 patients presenting with polyarthritis following COVID-19 infections with negative RA factor and anti-CCP, suggesting a diagnosis of inflammatory reactive arthritis. The authors proposed that the inflammatory reactive arthritis arose secondary to the involvement of pro-inflammatory markers, 1L-6 and TNF- $\alpha$, that are released due to COVID-19-related respiratory and musculoskeletal inflammation. These patients were treated with low-dose corticosteroids (prednisone $10 \mathrm{mg} / \mathrm{d}$ ), etoricoxib, disease modifying anti-rheumatic drugs (DMARDs), leflunomide $(20 \mathrm{mg} / \mathrm{d})$ and hydroxychloroquine $(400 \mathrm{mg} / \mathrm{d})$.

Corticosteroids may be given to COVID-19 patients for acute inflammation, but these medications can lead to muscle atrophy, muscle weakness, and decreased bone mineral density. Current studies are looking into the efficacy of tocilizumab, a monoclonal antibody against IL-6. This drug is currently approved for the treatment of rheumatoid arthritis and juvenile idiopathic arthritis to modulate joint inflammation, bone loss, and other manifestations of these diseases. Tocilizumab is being used in the treatment of COVID-19 because IL- 6 believed to be a key cytokine leading to an inflammatory cytokine storm. The goal of this treatment is to reduce the effects of COVID-19-induced cytokine storms.

\section{Arthralgias \& Myalgias}

Arthralgias or myalgias have been reported as symptoms in those infected with COVID-19, with one study finding that myalgia and/or arthralgia were present in $15.5 \%$ of patients. A systematic review and meta-analysis of 11,069 infected patients found the prevalence of myalgia to be present in $19 \%$ of patients. However, reporting of these two symptoms in the literature have often wrongly been grouped together or used interchangeably. It is important to make the distinction between arthralgia and myalgia as they are unique in the locations they present and their underlying physiology. Arthralgia is localized to the joints, while myalgia is localized to muscle. The literature has described how arthralgia and/or myalgia typically present in the early course of the disease, with some studies observing they present more commonly in females. Studies have also suggested that the presence of arthralgia may have an association with disease severity, although the evidence for this is scarce. One study found that the onset of arthralgia sometimes occurred days before or after the onset of fever and pulmonary symptoms in contrast to myalgia which has been reported to coincide with the occurrence of viral illness, which is an important distinguishing factor for clinicians to recognize. Furthermore, in patients experiencing long-term effects of COVID-19 or a prolonged disease course, $27 \%$ report ongoing joint pain. Patients with arthralgia also reported higher pain levels and required more analgesia. Therefore, it is imperative for clinicians to recognize this when diagnosing and managing patients with a history of COVID-19 infection who present with arthralgia and to adequately discern this finding from reactive arthritis.

The prevalence of arthralgia or myalgia in infected patients varies in the literature. In a single-center retrospective cohort study of 294 patients hospitalized with COVID19 , Hoong et al observed that $30 \%$ of patients reported musculoskeletal complaints. The authors found that of those with musculoskeletal complaints, $37.5 \%$ had myalgia, $5.7 \%$ arthralgia, 6.8\% new-onset backache and 50\% generalized body ache. Interestingly, the authors also found that patients with musculoskeletal symptoms had a higher prevalence of fever $(\mathrm{p}<0.01)$ and a higher CRP level $(\mathrm{p}<$ 0.01 ), and that the presence or absence of musculoskeletal symptoms was not a significant predictor of the risk of developing pneumonia. This highlights the importance of recognizing and understanding arthralgia and myalgia in patients at risk of COVID-19, even in the absence of pulmonary symptoms. In a retrospective study of 615 patients hospitalized for COVID-19 in Italy, De Rosa et al found that $2.8 \%$ of patients reported myalgia and/or arthralgia. Of note, the authors in that study did not find a statistically significant association with elevated serum creatine kinase (CK) levels. 
The authors also found that patients with history of falls had higher CK levels $(p<0.002)$ even if there was no clinical evidence of muscle trauma on ER reports and consequently may be an important factor for clinicians to consider. In a prospective observational cohort study of 1150 patients hospitalized for COVID-19 in New York City, Cummings et al found that $26 \%$ of patients reported myalgia. Another epidemiologic study of 1420 patients in Europe with mild-to -moderate COVID-19 infections found that $62.5 \%$ reported myalgia.

The mechanism behind the presence of myalgia or arthralgia with COVID-19 infection remains poorly understood. As a close relative to COVID-19, studies on SARSCoV-1 may provide insight into potential mechanisms of injury to the musculoskeletal system caused by COVID-19 infections. Previous studies on the SARS-CoV-1 virus have described how infection can lead to muscle damage or dysfunction, decreases in body mass, muscle fiber atrophy, or focal muscle fiber necrosis and immune cell infiltration. Studies have also described reports of patients with avascular necrosis, mostly in the femoral head, following SARS-CoV-1 infection, which may be due to the infection itself or the corticosteroid use in its treatment.

Furthermore, the inflammatory response to COVID-19 infection may be a contributor to myalgia and/or arthralgia in infected patients. Studies have described how those infected with COVID-19 can experience an aggressive inflammatory response, with elevated levels of proinflammatory signaling molecules such as CRP, IFN- $\gamma$, IL-1 $\beta$, IL-6, IL-17, and TNF- $\alpha$. These inflammatory signaling molecules have been linked to muscle fiber damage and consequently may play a role in causing or contributing to arthralgia and/or myalgia during COVID-19 infection.

The management of myalgia and/or arthralgia in patients infected with or having a history of COVID-19 remains largely unchanged and consists of NSAIDs and/or rehabilitation such as physical therapy. Caution should be taken in determining the etiology of the arthralgia and/or myalgia, and other causes such as reactive arthritis or inflammatory disease processes should be adequately explored.

\section{Musculoskeletal Sequelae of COVID Therapy}

Understanding the potential musculoskeletal sequelae of therapies used to treat and manage COVID-19 is imperative. Numerous medications are being investigated as potential therapeutic options for COVID-19 patients, including new investigational drugs and therapies being repurposed for COVID-19. Repurposed therapies, each with their unique side effect profile, include drugs such as chloroquine/hydroxychloroquine, Lopinavir/Ritonavir, Ribavirin, Interferon (IFN) $-\alpha$ and $-\beta$, and corticosteroid use. Studies have described how IFN- $\beta$ and IFN- $\alpha$ are associated with arthralgia and myalgia in patients undergoing its therapy. It has also been reported that, rarely, myopathy and neuromyopathy may occur following treatment with chloroquine and hydroxychloroquine. Although rare, it has been reported that Lopinavir-ritonavir treatment is associated with arthralgia, back pain and osteonecrosis. One study on the pharmacological profile of ribavirin found that for patients being treated with the drug, $>10 \%$ of patients reported arthralgia and musculoskeletal pain. Furthermore, a population cohort-based study in South Korea investigating pain medication use found that patients with comorbid musculoskeletal disorders who are infected with COVID-19 were not associated with increased in-hospital mortality. However, the authors found that strong opioid use was associated with higher inhospital mortality among patients, whereas use of other pain medications (paracetamol, gabapentin, pregabalin, glucocorticoids, NSAIDs, weak opioid, and benzodiazepine) did not show a significant association with inhospital mortality.

Corticosteroid use in the management of COVID-19 patients has increased, thus understanding its wide side effect profile is essential. Prolonged corticosteroid use, especially in critically ill patients, has been associated with a variety of effects on bone, including associations with osteonecrosis, reduced bone mineral density (BMD), and osteoporosis. Studies have described how corticosteroids can also lead to muscle atrophy and muscle weakness. Whether these effects are due to the use of corticosteroids specifically remains poorly understood, as it has also reported these effects occur in critically ill patients without the use of corticosteroids. As clinicians managing patients with musculoskeletal complaints, caution and consideration should be given to the use or history of corticosteroid therapy, and these patients should be monitored for long-term effects.

\section{Rehabilitation and Recovery}

Equally important for clinicians is understanding the potential long-term impact COVID-19 infection may have on patients and their recovery. In a single-center cohort study following the recovery of 300 patients 
hospitalized from COVID-19 infection, Karaarslan et al found that $56.3 \%$ of patients reported musculoskeletal complaints 1 month after discharge. The authors also found that the most common musculoskeletal complaints of patients recovering from infection included fatigue, followed by back pain, arthralgia, myalgia, low back pain, and neck pain. Notably, the authors also observed that the persistence of fatigue, myalgia, and arthralgia was associated with a higher BMI. In another case series following patients discharged from COVID-19 hospitalization in Italy, Carfi et al found that $23.7 \%$ of patients had persistent complaints of joint pain over a month following discharge. Another study of 110 patients reported that $22.7 \%$ of patients experienced ongoing myalgia following infection. Therefore, it is important for patients to consider a history of COVID-19 infection when managing patients with musculoskeletal complaints.
Rehabilitation programs may prove beneficial for patients with persistent musculoskeletal complaints recovering from COVID-19 infection. Past studies investigating recovery following SARS-CoV-1 infection have observed improvement of symptoms in recovering patients. In one randomized control trial evaluating the effect of an exercise training program on cardiorespiratory and musculoskeletal recovery following SARS-CoV-1 infection, Lau et al found that exercise training program was effective in improving both the cardiorespiratory and musculoskeletal fitness. Consequently, there may be similar benefit for patients recovering from COVID-19 infection. Additionally, preventing prolonged physical inactivity in recovering patients may prove beneficial in preventing muscle disuse atrophy and loss in functional performance. Furthermore, long-term monitoring and follow-up chest imaging may be warranted for patients

Table I Summary of COVID-I9 Effects on the Musculoskeletal System

\begin{tabular}{|c|c|}
\hline $\begin{array}{l}\text { Neuromuscular involvement: } \\
\text { neuropathies \& myopathies }\end{array}$ & $\begin{array}{l}\text { - COVID-I9 patients admitted to the ICU that have undergone invasive ventilation and pronation cycles } \\
\text { are at increased risk of critical illness myopathy (CIM) and critical illness polyneuropathy (CIP), and more } \\
\text { rarely Guillain Barre Syndrome. } \\
\text { - In cases of uncooperative or sedated patients, electromyography and single nerve conduction studies } \\
\text { can be used for diagnosis. } \\
\text { - Management of CIM and CIP includes reducing the time a patient spends in an immobilized state and } \\
\text { pulmonary rehabilitation/early mobilization. }\end{array}$ \\
\hline Inflammation impact on MSK & $\begin{array}{l}\text { - COVID- } 19 \text { induced proinflammatory state may lead to inflammatory reactive arthritis, muscle fibrosis, } \\
\text { increased bone fragility, tendinopathy, and muscle weakness. }\end{array}$ \\
\hline Arthralgias \& myalgias & $\begin{array}{l}\text { - Arthralgia and myalgia commonly present early in COVID-19 patients, even in the absence of } \\
\text { pulmonary symptoms, with myalgia occurring more commonly. } \\
\text { - Studies have suggested that arthralgia can precede the onset of fever and pulmonary symptoms in } \\
\text { infected patients. } \\
\text { - Management of myalgia and/or arthralgia in patients with a history of COVID-19 consists of NSAIDs } \\
\text { and/or rehabilitation. }\end{array}$ \\
\hline $\begin{array}{l}\text { Musculoskeletal sequelae of COVID } \\
\text { therapy }\end{array}$ & $\begin{array}{l}\text { - The use of IFN- } \beta \text { and IFN- } \alpha \text { as therapy for COVID-I } 9 \text { may be associated with arthralgia and myalgia in } \\
\text { patients. } \\
\text { - It has been reported that in patients being treated with ribavirin, }>10 \% \text { of patients reported arthralgia } \\
\text { and musculoskeletal pain. } \\
\text { - Care should be given with opioid use, as strong opioid use was associated with higher in-hospital mortality, } \\
\text { whereas other pain medications did not show a significant association with in-hospital mortality. } \\
\text { - Prolonged corticosteroid use has been associated with various effects on bone and muscle, including } \\
\text { associations with osteonecrosis, reduced bone mineral density, osteoporosis, muscle atrophy, and muscle } \\
\text { weakness. }\end{array}$ \\
\hline Rehabilitation and recovery & $\begin{array}{l}\text { - Musculoskeletal symptoms may continue to persist following recovery from COVID-19, with the most } \\
\text { common complaints including fatigue, back pain, arthralgia, myalgia, low back pain, and neck pain. } \\
\text { - Rehabilitation can improve persistent musculoskeletal symptoms, including exercise training programs } \\
\text { and/or physical therapy. } \\
\text { - Prevention of prolonged physical inactivity may assist in minimizing muscle disuse atrophy and loss in } \\
\text { functional performance. }\end{array}$ \\
\hline
\end{tabular}


recovering from severe illness. One study of patients recovering from both SARS-CoV-1 and Middle East respiratory syndrome (MERS) found fibrosis was a common finding in patients who experienced persistent pulmonary symptoms. Therefore, special attention should be paid to patients experiencing persistent pulmonary symptoms.

\section{Conclusion}

As the global pandemic caused by COVID-19 continues to leave its mark on the world, special attention must be given to its musculoskeletal effects. Infection with the virus can cause a range of musculoskeletal symptoms such as arthralgias, myalgias, neuropathies/myopathies, and potential bone and joint damage (Table 1). Importantly, current therapeutics used in the management of COVID-19 patients can also cause musculoskeletal effects that clinicians should be aware of. Finally, understanding the need for effective rehabilitation is critical in helping patients return to pre-infection mobility and function.

\section{Acknowledgment}

The authors would like to acknowledge The Cappo Family Research Fund.

\section{Disclosure}

None of the authors report any conflict of interest related to this study.

\section{References}

1. Huang C, Wang Y, Li X, et al. Clinical features of patients infected with 2019 novel coronavirus in Wuhan, China. Lancet. 2020;395 (10223):497-506. doi:10.1016/s0140-6736(20)30183-5

2. Sun P, Qie S, Liu Z, Ren J, Li K, Xi J. Clinical characteristics of hospitalized patients with SARS-CoV-2 infection: a single arm meta-analysis. J Med Virol. 2020;92(6):612-617. doi:10.1002/jmv. 25735

3. White-Dzuro G, Gibson LE, Zazzeron L, et al. Multisystem effects of COVID-19: a concise review for practitioners. Postgrad Med. 2021;133(1):20-27. doi:10.1080/00325481.2020.1823094

4. Zhu J, Ji P, Pang J, et al. Clinical characteristics of 3062 COVID-19 patients: a meta-analysis. J Med Virol. 2020;92(10):1902-1914. doi:10.1002/jmv. 25884

5. Shen J, Abu-Amer Y, O'Keefe RJ, McAlinden A. Inflammation and epigenetic regulation in osteoarthritis. Connect Tissue Res. 2017;58 (1):49-63. doi:10.1080/03008207.2016.1208655

6. Scanzello CR. Chemokines and inflammation in osteoarthritis: insights from patients and animal models. J Orthop Res. 2017;35(4):735-739. doi:10.1002/jor.23471

7. Redlich K, Smolen JS. Inflammatory bone loss: pathogenesis and therapeutic intervention. Nat Rev Drug Discov. 2012;11(3):234-250. doi: $10.1038 / \mathrm{nrd} 3669$
8. Parasher A. COVID-19: current understanding of its pathophysiology, clinical presentation and treatment. Postgrad Med J. 2021;97 (1147):312-320. doi:10.1136/postgradmedj-2020-138577

9. Mehta OP, Bhandari P. Coronavirus Disease (COVID-19): Comprehensive Review of Clinical Presentation. Front Public Health. 2020;8(2):582932. doi:10.3389/fpubh.2020.582932

10. Disser NP, De Micheli AJ, Schonk MM, et al. Musculoskeletal consequences of COVID-19. J Bone Joint Surg Am. 2020;102 (14):1197-1204. doi:10.2106/jbjs.20.00847

11. Jin Y, Yang H, Ji W, et al. Virology, epidemiology, pathogenesis, and control of COVID-19. Viruses. 2020;12(4):372. doi:10.3390/v12040372

12. Tay MZ, Poh CM, Rénia L, MacAry PA, Ng LFP. The trinity of COVID-19: immunity, inflammation and intervention. Nat Rev Immunol. 2020;20(6):363-374. doi:10.1038/s41577-020-0311-8

13. Lin L, Lu L, Cao W, Li T. Hypothesis for potential pathogenesis of SARS-CoV-2 infection-a review of immune changes in patients with viral pneumonia. Emerg Microbes Infect. 2020;9(1):727-732. doi:10.1080/22221751.2020.1746199

14. Perandini LA, Chimin P, Lutkemeyer DDS, Câmara NOS. Chronic inflammation in skeletal muscle impairs satellite cells function during regeneration: can physical exercise restore the satellite cell niche? FEBS J. 2018;285(11):1973-1984. doi:10.1111/febs.14417

15. Hanaoka BY, Ithurburn MP, Rigsbee CA, et al. Chronic inflammation in rheumatoid arthritis and mediators of skeletal muscle pathology and physical impairment: a review. Arthritis Care Res (Hoboken). 2019;71(2):173-177. doi:10.1002/acr.23775

16. Doughty CT, Amato AA. Toxic myopathies. Continuum (Minneap Minn). 2019;25(6):1712-1731. doi:10.1212/con.0000000000000806

17. McClafferty B, Umer I, Fye G, et al. Approach to critical illness myopathy and polyneuropathy in the older SARS-CoV-2 patients. J Clin Neurosci. 2020;79:241-245. doi:10.1016/j.jocn.2020.07.058

18. Cabañes-Martínez L, Villadóniga M, González-Rodríguez L, et al. Neuromuscular involvement in COVID-19 critically ill patients. Clin Neurophysiol. 2020;131(12):2809-2816. doi:10.1016/j.clinph.2020.09. 017

19. Abdullahi A, Candan SA, Abba MA, et al. Neurological and musculoskeletal features of COVID-19: a systematic review and meta-analysis. Front Neurol. 2020;11:687. doi:10.3389/fneur.2020.00687

20. Tankisi H, Tankisi A, Harbo T, Markvardsen LK, Andersen H, Pedersen TH. Critical illness myopathy as a consequence of Covid-19 infection. Clin Neurophysiol. 2020;131(8):1931-1932. doi:10.1016/j.clinph.2020.06.003

21. Nasuelli NA, Pettinaroli R, Godi L, et al. Critical illness neuro-myopathy (CINM) and focal amyotrophy in intensive care unit (ICU) patients with SARS-CoV-2: a case series. Neurol Sci. 2021;42(3):1119-1121. doi:10.1007/s10072-020-04820-9

22. Yang T, Li Z, Jiang L, Wang Y, Xi X. Risk factors for intensive care unit-acquired weakness: a systematic review and meta-analysis. Acta Neurol Scand. 2018;138(2):104-114. doi:10.1111/ane.12964

23. Vanhorebeek I, Latronico N, Van den Berghe G. ICU-acquired weakness. Intensive Care Med. 2020;46(4):637-653. doi:10.1007/ s00134-020-05944-4

24. Bellido V, Pérez A. Inpatient hyperglycemia management and COVID-19. Diabetes Ther. 2021;12(1):121-132. doi:10.1007/s133 00-020-00966-z

25. Wunsch H. Mechanical ventilation in COVID-19: interpreting the current epidemiology. Am J Respir Crit Care Med. 2020;202 (1):1-4. doi:10.1164/rccm.202004-1385ED

26. Iwasaki M, Saito J, Zhao H, Sakamoto A, Hirota K, Ma D. Inflammation triggered by SARS-CoV-2 and ACE2 augment drives multiple organ failure of severe COVID-19: molecular mechanisms and implications. Inflammation. 2021;44(1):13-34. doi:10.1007/s10753-020-01337-3

27. Thibault R, Seguin P, Tamion F, Pichard C, Singer P. Nutrition of the COVID-19 patient in the intensive care unit (ICU): a practical guidance. Crit Care. 2020;24(1):447. doi:10.1186/s13054-020-03 $159-\mathrm{z}$ 
28. Hu B, Huang S, Yin L. The cytokine storm and COVID-19. J Med Virol. 2021;93(1):250-256. doi:10.1002/jmv.26232

29. Van Aerde N, Van den Berghe G, Wilmer A, Gosselink R, Hermans G. Intensive care unit acquired muscle weakness in COVID-19 patients. Intensive Care Med. 2020;46(11):2083-2085. doi:10.1007/s00134-020-06244-7

30. Wieske L, Dettling-Ihnenfeldt DS, Verhamme C, et al. Impact of ICU-acquired weakness on post-ICU physical functioning: a follow-up study. Crit Care. 2015;19(1):196. doi:10.1186/s13054015-0937-2

31. Anekwe DE, Biswas S, Bussières A, Spahija J. Early rehabilitation reduces the likelihood of developing intensive care unit-acquired weakness: a systematic review and meta-analysis. Physiotherapy. 2020;107:1-10. doi:10.1016/j.physio.2019.12.004

32. Agosti E, Giorgianni A, D'Amore F, Vinacci G, Balbi S, Locatelli D. Is Guillain-Barrè syndrome triggered by SARS-CoV-2? Case report and literature review. Neurol Sci. 2021;42(2):607-612. doi:10.1007/ s10072-020-04553-9

33. Alberti P, Beretta S, Piatti M, et al. Guillain-Barré syndrome related to COVID-19 infection. Neurol Neuroimmunol Neuroinflamm. 2020;7(4):e741. doi:10.1212/nxi.0000000000000741

34. Arnaud S, Budowski C, Ng Wing Tin S, Degos B. Post SARS-CoV-2 Guillain-Barré syndrome. Clin Neurophysiol. 2020;131(7):16 52-1654. doi:10.1016/j.clinph.2020.05.003

35. Assini A, Benedetti L, Di Maio S, Schirinzi E, Del Sette M. New clinical manifestation of COVID-19 related Guillain-Barrè syndrome highly responsive to intravenous immunoglobulins: two Italian cases. Neurol Sci. 2020;41(7):1657-1658. doi:10.1007/ s10072-020-04484-5

36. Bigaut K, Mallaret M, Baloglu S, et al. Guillain-Barré syndrome related to SARS-CoV-2 infection. Neurol Neuroimmunol Neuroinflamm. 2020;7(5):e785. doi:10.1212/nxi.0000000000000785

37. Abu-Rumeileh S, Abdelhak A, Foschi M, Tumani H, Otto M. Guillain-Barré syndrome spectrum associated with COVID-19: an up-to-date systematic review of 73 cases. J Neurol. 2021;268 (4):1133-1170. doi:10.1007/s00415-020-10124-x

38. Sejvar JJ, Baughman AL, Wise M, Morgan OW. Population incidence of Guillain-Barré syndrome: a systematic review and metaanalysis. Neuroepidemiology. 2011;36(2):123-133. doi:10.1159/ 000324710

39. Paliwal VK, Garg RK, Gupta A, Tejan N. Neuromuscular presentations in patients with COVID-19. Neurol Sci. 2020;41 (11):3039-3056. doi:10.1007/s10072-020-04708-8

40. Tao H, Bai J, Zhang W, et al. Bone biology and COVID-19 infection: is ACE2 a potential influence factor? Med Hypotheses. 2020; 144:110178. doi:10.1016/j.mehy.2020.110178

41. Orford N, Cattigan C, Brennan SL, Kotowicz M, Pasco J, Cooper DJ. The association between critical illness and changes in bone turnover in adults: a systematic review. Osteoporos Int. 2014;25(10):23 35-2346. doi:10.1007/s00198-014-2734-1

42. Orford NR, Pasco JA, Kotowicz MA. Osteoporosis and the critically ill patient. Crit Care Clin. 2019;35(2):301-313. doi:10.1016/j. ccc.2018.11.006

43. Hiraga T. Hypoxic microenvironment and metastatic bone disease. Int J Mol Sci. 2018;19(11):3523. doi:10.3390/ijms19113523

44. Tao H, Ge G, Li W, et al. Dysimmunity and inflammatory storm: watch out for bone lesions in COVID-19 infection. Med Hypotheses. 2020;145:110332. doi:10.1016/j.mehy.2020.110332

45. Gallardo E, de Andrés I, Illa I. Cathepsins are upregulated by IFN-gamma/STAT1 in human muscle culture: a possible active factor in dermatomyositis. J Neuropathol Exp Neurol. 2001;60(9):847-855. doi:10.1093/jnen/60.9.847

46. Authier FJ, Chazaud B, Plonquet A, et al. Differential expression of the IL-1 system components during in vitro myogenesis: implication of IL-1beta in induction of myogenic cell apoptosis. Cell Death Differ. 1999;6(10):1012-1021. doi:10.1038/sj.cdd.4400576
47. Forcina L, Miano C, Scicchitano BM, et al. Increased circulating levels of interleukin-6 affect the redox balance in skeletal muscle. Oxid Med Cell Longev. 2019;2019:3018584. doi:10.1155/2019/ 3018584

48. Tang H, Pang S, Wang M, et al. TLR4 activation is required for IL-17-induced multiple tissue inflammation and wasting in mice. J Immunol. 2010;185(4):2563-2569. doi:10.4049/jimmunol.0903664

49. Reid MB, Li YP. Tumor necrosis factor-alpha and muscle wasting: a cellular perspective. Respir Res. 2001;2(5):269-272. doi:10.1186/ rr67

50. Otis JS, Niccoli S, Hawdon N, et al. Pro-inflammatory mediation of myoblast proliferation. PLoS One. 2014;9(3):e92363. doi:10.1371/ journal.pone. 0092363

51. Gilbert L, He X, Farmer P, et al. Inhibition of osteoblast differentiation by tumor necrosis factor-alpha. Endocrinology. 2000;141 (11):3956-3964. doi:10.1210/endo.141.11.7739

52. Kotake S, Udagawa N, Takahashi N, et al. IL-17 in synovial fluids from patients with rheumatoid arthritis is a potent stimulator of osteoclastogenesis. J Clin Invest. 1999;103(9):1345-1352. doi:10. $1172 /$ jci5703

53. Liu P, Lee S, Knoll J, et al. Loss of menin in osteoblast lineage affects osteocyte-osteoclast crosstalk causing osteoporosis. Cell Death Differ. 2017;24(4):672-682. doi:10.1038/cdd.2016.165

54. Grange L, Nguyen MV, Lardy B, et al. NAD(P)H oxidase activity of Nox4 in chondrocytes is both inducible and involved in collagenase expression. Antioxid Redox Signal. 2006;8(9-10):1485-1496. doi:10. 1089/ars.2006.8.1485

55. Latourte A, Cherifi C, Maillet J, et al. Systemic inhibition of IL-6/ Stat3 signalling protects against experimental osteoarthritis. Ann Rheum Dis. 2017;76(4):748-755. doi:10.1136/annrheumdis-2016209757

56. Aizawa T, Kon T, Einhorn TA, Gerstenfeld LC. Induction of apoptosis in chondrocytes by tumor necrosis factor-alpha. J Orthop Res. 2001;19(5):785-796. doi:10.1016/s0736-0266(00)00078-4

57. Zhang K, Asai S, Yu B, Enomoto-Iwamoto M. IL-1 $\beta$ irreversibly inhibits tenogenic differentiation and alters metabolism in injured tendon-derived progenitor cells in vitro. Biochem Biophys Res Commun. 2015;463(4):667-672. doi:10.1016/j.bbrc.2015.05.122

58. Millar NL, Akbar M, Campbell AL, et al. IL-17A mediates inflammatory and tissue remodelling events in early human tendinopathy. Sci Rep. 2016;6(1):27149. doi:10.1038/srep27149

59. Backman LJ, Eriksson DE, Danielson P. Substance P reduces TNF- $\alpha$ induced apoptosis in human tenocytes through NK-1 receptor stimulation. Br J Sports Med. 2014;48(19):1414-1420. doi:10.1136/ bjsports-2013-092438

60. Mukarram MS, Ishaq Ghauri M, Sethar S, Afsar N, Riaz A, Ishaq K. COVID-19: an emerging culprit of inflammatory arthritis. Case Rep Rheumatol. 2021;2021:6610340. doi:10.1155/2021/6610340

61. Saricaoglu EM, Hasanoglu I, Guner R. The first reactive arthritis case associated with COVID-19. J Med Virol. 2021;93(1):192-193. doi: $10.1002 / \mathrm{jmv} .26296$

62. Ono K, Kishimoto M, Shimasaki T, et al. Reactive arthritis after COVID-19 infection. RMD Open. 2020;6(2):e001350. doi:10.1136/ rmdopen-2020-001350

63. Mukarram I, Mukarram M, Ishaq K, Riaz S. Post COVID-19 reactive arthritis: an emerging existence in the spectrum of musculoskeletal complications of SARS-CoV-2 infection. J Clin Stud Med Case Rep. 2020;7(101):2.

64. Campochiaro C, Della-Torre E, Cavalli G, et al. Efficacy and safety of tocilizumab in severe COVID-19 patients: a single-centre retrospective cohort study. Eur J Intern Med. 2020;76:43-49. doi:10.1016/ j.ejim.2020.05.021

65. Biggioggero M, Crotti C, Becciolini A, Favalli EG. Tocilizumab in the treatment of rheumatoid arthritis: an evidence-based review and patient selection. Drug Des Devel Ther. 2019;13:57-70. doi:10.2147/ dddt.S150580 
66. Xu X, Han M, Li T, et al. Effective treatment of severe COVID-19 patients with tocilizumab. Proc Natl Acad Sci U S A. 2020;117 (20):10970-10975. doi:10.1073/pnas.2005615117

67. Tuzun S, Keles A, Okutan D, Yildiran T, Palamar D. Assessment of musculoskeletal pain, fatigue and grip strength in hospitalized patients with COVID-19. Eur J Phys Rehabil Med. 2021;57 (4):653-662. doi:10.23736/s1973-9087.20.06563-6

68. Hoong CWS, Amin M, Tan TC, Lee JE. Viral arthralgia a new manifestation of COVID-19 infection? A cohort study of COVID-19associated musculoskeletal symptoms. Int $J$ Infect Dis. 2021;104:363-369. doi:10.1016/j.ijid.2021.01.031

69. Carfì A, Bernabei R, Landi F. Persistent symptoms in patients after acute COVID-19. JAMA. 2020;324(6):603-605. doi:10.1001/jama. 2020.12603

70. Greenhalgh T, Knight M, A'Court C, Buxton M, Husain L. Management of post-acute covid-19 in primary care. BMJ. 2020;370:m3026. doi:10.1136/bmj.m3026

71. De Rosa A, Verrengia EP, Merlo I, et al. Muscle manifestations and CK levels in COVID infection: results of a large cohort of patients inside a pandemic COVID-19 area. Acta Myol. 2021;40(1):1-7. doi: $10.36185 / 2532-1900-040$

72. Cummings MJ, Baldwin MR, Abrams D, et al. Epidemiology, clinical course, and outcomes of critically ill adults with COVID-19 in New York City: a Prospective Cohort Study. Lancet. 2020;395 (10239):1763-1770. doi:10.1016/s0140-6736(20)31189-2

73. Lechien JR, Chiesa-Estomba CM, Place S, et al. Clinical and epidemiological characteristics of 1420 European patients with mild-tomoderate coronavirus disease 2019. J Intern Med. 2020;288 (3):335-344. doi:10.1111/joim.13089

74. McCray PB Jr, Pewe L, Wohlford-Lenane C, et al. Lethal infection of K18-hACE2 mice infected with severe acute respiratory syndrome coronavirus. J Virol. 2007;81(2):813-821. doi:10.1128/jvi.02012-06

75. Leung TW, Wong KS, Hui AC, et al. Myopathic changes associated with severe acute respiratory syndrome: a postmortem case series. Arch Neurol. 2005;62(7):1113-1117. doi:10.1001/archneur.62.7.1113

76. Ding Y, Wang H, Shen H, et al. The clinical pathology of severe acute respiratory syndrome (SARS): a report from China. J Pathol. 2003;200(3):282-289. doi:10.1002/path.1440

77. Lv H, de Vlas SJ, Liu W, et al. Avascular osteonecrosis after treatment of SARS: a 3-Year Longitudinal Study. Trop Med Int Health. 2009;14 Suppl 1(Suppl1):79-84. doi:10.1111/j.1365-3156.2008.02187.x

78. Guo KJ, Zhao FC, Guo Y, Li FL, Zhu L, Zheng W. The influence of age, gender and treatment with steroids on the incidence of osteonecrosis of the femoral head during the management of severe acute respiratory syndrome: a retrospective study. Bone Joint J. 2014;96-b (2):259-262. doi:10.1302/0301-620x.96b2.31935

79. Griffith JF. Musculoskeletal complications of severe acute respiratory syndrome. Semin Musculoskelet Radiol. 2011;15(5):554-560. doi:10. 1055/s-0031-1293500

80. Zhou J, Liu B, Liang C, Li Y, Song YH. Cytokine signaling in skeletal muscle wasting. Trends Endocrinol Metab. 2016;27 (5):335-347. doi:10.1016/j.tem.2016.03.002

81. Sanders JM, Monogue ML, Jodlowski TZ, Cutrell JB. Pharmacologic treatments for coronavirus disease 2019 (COVID-19): a review. JAMA. 2020;323(18):1824-1836. doi:10.1001/jama.2020.6019

82. Munschauer FE 3rd, Kinkel RP. Managing side effects of interferon-beta in patients with relapsing-remitting multiple sclerosis. Clin Ther. 1997;19(5):883-893. doi:10.1016/s0149-2918(97)80042-2

83. Nikfar S, Rahimi R, Abdollahi M. A meta-analysis of the efficacy and tolerability of interferon- $\beta$ in multiple sclerosis, overall and by drug and disease type. Clin Ther. 2010;32(11):1871-1888. doi:10. 1016/j.clinthera.2010.10.006
84. Dusheiko G. Side effects of alpha interferon in chronic hepatitis C. Hepatology. 1997;26(3Suppl 1):112s-121s. doi:10.1002/hep.5102 60720

85. Psarras A, Emery P, Vital EM. Type I interferon-mediated autoimmune diseases: pathogenesis, diagnosis and targeted therapy. Rheumatology (Oxford). 2017;56(10):1662-1675. doi:10.1093/rheumatology/kew431

86. Casado E, Gratacós J, Tolosa C, et al. Antimalarial myopathy: an underdiagnosed complication? Prospective longitudinal study of 119 patients. Ann Rheum Dis. 2006;65(3):385-390. doi:10.1136/ard.20 04.023200

87. Chandwani A, Shuter J. Lopinavir/ritonavir in the treatment of HIV-1 infection: a review. Ther Clin Risk Manag. 2008;4(5):1023-1033. doi: $10.2147 /$ tcrm.s3285

88. Naik GS, Tyagi MG. A pharmacological profile of ribavirin and monitoring of its plasma concentration in chronic hepatitis C infection. J Clin Exp Hepatol. 2012;2(1):42-54. doi:10.1016/s09736883(12)60090-5

89. Oh TK, Song IA, Lee J, Eom W, Jeon YT. Musculoskeletal disorders, pain medication, and in-hospital mortality among patients with COVID-19 in South Korea: a Population-Based Cohort Study. Int J Environ Res Public Health. 2021;18(13):6804. doi:10.3390/ ijerph18136804

90. van Paassen J, Vos JS, Hoekstra EM, Neumann KMI, Boot PC, Arbous SM. Corticosteroid use in COVID-19 patients: a systematic review and meta-analysis on clinical outcomes. Crit Care. 2020;24 (1):696. doi:10.1186/s13054-020-03400-9

91. Lau EM, Chan FW, Hui DS, Wu AK, Leung PC. Reduced bone mineral density in male Severe Acute Respiratory Syndrome (SARS) patients in Hong Kong. Bone. 2005;37(3):420-424. doi:10.1016/j.bone.2005.04.018

92. Karaarslan F, Demircioğlu Güneri F, Kardeş S. Postdischarge rheumatic and musculoskeletal symptoms following hospitalization for COVID-19: prospective follow-up by phone interviews. Rheumatol Int. 2021;41(7):1263-1271. doi:10.1007/s00296-021-04882-8

93. Arnold DT, Hamilton FW, Milne A, et al. Patient outcomes after hospitalisation with COVID-19 and implications for follow-up: results from a prospective UK cohort. Thorax. 2021;76(4):399-401. doi:10.1136/thoraxjnl-2020-216086

94. Lau HM, Ng GY, Jones AY, Lee EW, Siu EH, Hui DS. A randomised controlled trial of the effectiveness of an exercise training program in patients recovering from severe acute respiratory syndrome. Aust $J$ Physiother. 2005;51(4):213-219. doi:10.1016/s0004-9514(05)70 002-7

95. Rooney S, Webster A, Paul L. Systematic review of changes and recovery in physical function and fitness after severe acute respiratory syndrome-related coronavirus infection: implications for COVID-19 rehabilitation. Phys Ther. 2020;100(10):1717-1729. doi:10.1093/ptj/pzaa129

96. Mulcahey MK, Gianakos AL, Mercurio A, Rodeo S, Sutton KM. Sports medicine considerations during the COVID-19 pandemic. Am J Sports Med. 2021;49(2):512-521. doi:10.1177/0363546520975186

97. Hosseiny M, Kooraki S, Gholamrezanezhad A, Reddy S, Myers L. Radiology perspective of coronavirus disease 2019 (COVID-19): lessons from severe acute respiratory syndrome and middle east respiratory syndrome. AJR Am J Roentgenol. 2020;214(5):10 78-1082. doi:10.2214/ajr.20.22969 


\section{Publish your work in this journal}

Orthopedic Research and Reviews is an international, peer-reviewed, open access journal that focusing on the patho-physiology of the musculoskeletal system, trauma, surgery and other corrective interventions to restore mobility and function. Advances in new technologies, materials, techniques and pharmacological agents are particularly

Submit your manuscript here: https://www.dovepress.com/orthopedic-research-and-reviews-journa welcome. The manuscript management system is completely online and includes a very quick and fair peer-review system, which is all easy to use. Visit http://www.dovepress.com/testimonials.php to read real quotes from published authors. 